\title{
Introduction: Philosophy for Finance
}

\author{
Emiliano Ippoliti $^{1}$
}

Published online: 16 August 2021

(C) The Author(s), under exclusive licence to Springer Nature B.V. 2021
The reactions to financial systems have varied between radically negative, pragmatically moderate, and generally positive $(\S 1)$. These three stances display different philosophical approaches to finance and also the interdependence between finance and philosophy (\$2). On this basis, I outline the role that philosophy plays for financial practice and vice versa ( $\S 3)$, and I explore the specific dynamics of a 'reverse finance' (§4) and interesting philosophical consequences of it (§5). Moreover, I discuss some recent contributions to a few main issues in the emerging field of the philosophy of finance (§6), in particular in ontology, methodology, ethics, mathematical modelling, and algorithmic finance.

\section{Three Philosophical Stances on Finance}

Financial systems are not only a central infrastructure of contemporary economies but they have also become an organizing principle of advanced modern societies. This role is also the outcome of a historical change in the philosophical and moral attitudes towards them (Brook 2011; De Bruin et al. 2018; Ferguson 2008; Garonna and Spaolonzi 2016). In effect, philosophy played a driving role in the acceptance and dissemination of financial systems. In particular, there are three main philosophical stances on finance-radically negative, pragmatically moderate, and generally positive-, which express different reactions that the ascent of finance arouses.

The first, the radically negative one, considers financial systems as an evil, or a sin in several religions, and therefore as something that has to be banned because morally unacceptable, as for example advocated by Aristotle in his Politics. Ideas such as interest (making money from money) or worse usury, are expression of sheer personal ambition and

Emiliano Ippoliti

emi.ippoliti@gmail.com

1 Sapienza University of Rome, Rome, Italy are contrary to the morality that should be at the foundation of a fair society.

The pragmatically moderate view—advocated by Keynes (1936) among others - considers finance as a necessary evil (Kinley 2018). In effect, even if finance is not good in itself, it is necessary since borrowing money is useful socially and economically because it offers advantages such as addressing income or wealth shortages, long-term investment, and supporting economic growth. In this sense, finance is a means to move towards a world where the accumulation of wealth will become less and less important, and where the 'evil' on which it thrives_-greed, short-termism, adventurism, low sense of responsibility, excessive risk-taking-will be progressively abandoned and looked back on as primitive.

The generally positive view considers finance not only as an essential propellant for economic growth, a 'golden straitjacket' (Friedman 1999), but it also argues for the centrality of finance to all elements of human history (Ferguson 2008). This approach states that the path to economic prosperity is clear albeit narrow, and it may also need to satisfy global investors whose identity is unknown.

The acceptance and dissemination of financial systems, and the transition from the first to the third attitude, were made possible also by a series of philosophical changes. Here I recall two that are particularly important, that is, the separation between interest and usury, and the idea of selfinterest as a way of promoting of public good.

The separation between the notion of interest and that of usury, occurring in Late Middle Ages and the Renaissance, promoted the idea that a form of compensation (the interest) is legitimate for those who lend money because of the possible damages or losses that they can suffer, as the lenders participate in almost all the risks that a company takes. In this light, finance is an essential means to create prosperity and well-being. Interest and usury have been defined and measured in different ways in different societies and periods, but the crucial theoretical node here is the moral acceptability and distinction of what is allowed (interest) and what is not (usury) and therefore bad. 
The second important passage is the introduction of Smith's invisible hand, which shows that the very basis of finance, self-interest, can promote public good. In effect, Smith (1759) shows that self-interest elevates social wellbeing despite the fact that individuals do not intentionally aim to achieving it. Although we know that the invisible hand, and the first theorem of the welfare economy that formalizes it (Mas-Colell et al. 1995), are controversial and not realistic, they played an important role to disseminate the idea that finance is acceptable as not contrary to common good.

\section{Finance and the need for philosophy}

The financialization of the word (Epstein 2005), the controversial idea of finance as the organizing principle of modern societies, has intertwined finance with every aspects of the life of people, institutions and societies. This centrality of the financial system raises many issues that are philosophical in kind, that is, ethical, political, epistemological, methodological (see De Bruin et al. 2018 and Ippoliti 2020 for an overview).

Nonetheless, finance is produced by human beings, and as such it can be modified and improved, and philosophy can guide us to understand it better by examining not only what financial systems are but also what they could and should be.

Moreover, finance is still a young and under construction field. This is demonstrated by the kaleidoscope of theories developed to approach the problems of financial systems - the efficient markets hypothesis (e.g. Fama 1970), the reflexive market hypothesis (e.g. Soros 1987), the financial instability hypothesis (Minsky 1980), the econophysics hypothesis (Sornette 2003), the behavioral finance (e.g. Ackert and Deaves 2009), the adaptive market hypothesis (Lo 2004), just to mention a few of them. These different theories are not necessarily in conflict: some may be complementary, or point to different aspects of the same situation, or give us several views on different configurations of the same financial 'objects' or problems. Such a variety of financial theories suggest that a philosophical reflection on finance is not only useful, but necessary. In effect, philosophy serves not only to clarify concepts, or to investigate the assumptions underlying certain theories, but especially to open new lines of research at the 'frontier of knowledge', where many problems are still open, and the objects of inquiry are unclear. Finance is just in such a theoretical position right now, and philosophy can and should step in.

It is worth noting that the reverse is also true. Financial phenomena offer interesting material for philosophical debate-for instance in ontology, methodology, epistemology, and theory-building. Just to mention two examples, finance raises interesting questions about the relationship between data and hypotheses (Ippoliti 2019) or the relationship between the three fundamental notions such as explanation, prediction and control (§5).

\section{Theory and Practice never Sleep in Finance}

One of the most interesting issue in financial systems, and especially stock markets, is the relation between theory and practice-the theoretical products and the world. The presence of performative and constructive mechanisms in finance make theoretical tools able to shape social interactions in a way that is hard to experience in other social domains. In particular, the employment in the financial markets of models ${ }^{1}$ and socio-technical devices, like algorithms or formulas, can generate dynamics ${ }^{2}$ that raises a crucial issue, namely the possible production in 'reality', i.e. the financial system, of the outcome predicted or expected by these models. This property makes theory and practice so intertwined in finance that one can operate on the theoretical product, a model, to adjust the world (Boldyrev and Ushakov 2016): there is a continual and mutual influence of practice and theory in financial systems. This interplay opens the way to a specific scenario that can be labelled 'reverse finance' (Ippoliti 2019).

\section{Reversing Finance}

If we accept the thesis that theoretical tools are able to shape social interactions in the way predicted by them, then it follows that a market can be designed in a way that pushes financial actors to fit in with the theorical product, rather than vice versa. When this happens, a sort of 'reverse finance' emerges, whereby we start from the model and then we try to produce the corresponding 'reality', or better, we start from the wanted outcome, the one predicted by the model, and then we try to design or engineering as much as possible (with norms, rules, technologies) the hypotheses of the model needed to produce that outcome so that the market will behave as the model predicts. This way of addressing problems in finance is based on inversion heuristics, which works backwards by reversing the relation between model and reality, that is, it starts from the model and construct the corresponding 'reality' (e.g. Boldyrev and Ushakov 2016).

In more detail, reverse finance can investigate what are the possible initial conditions, and the possible or actual

\footnotetext{
${ }^{1}$ See Brisset (2018), Svetlova (2012), Svetlova and Dirksen (2014).

2 See Callon (1998, 2007), MacKenzie (2006), MacKenzie et al. (2008), Brisset (2019).
} 
process, to obtain an intended result. Or better, it can investigate which hypotheses (conditions) are necessary to get a specific financial result, which is the starting point of the investigation. Thus, we set a wanted goal and then we try to find the hypotheses and processes that, if satisfied, would produce it. Moreover, since an outcome $\mathrm{T}$ can be obtained from several sets of initial conditions (hypotheses), reverse finance can tell us what is a minimal "natural' ${ }^{3}$ set of them that is capable of getting $\mathrm{T}$. In doing so, it can show that specific hypotheses are necessary for $\mathrm{T}$, while others are not, and that they can be eliminated or replaced with other ones.

In order to be effective, this reversal has to specify how processes and conditions that are possible can become actual (and then what normative context, rules, conditions of a market must hold or change at a given time). One factor for reversing finance is the time horizon of these condition and processes: as the time horizon increases, the possible reversal becomes less and less likely.

Therefore, reverse finance can tell us when and how it is possible to transform a model that describes only possible or credible initial conditions, possible process, abstract result - that is, a non-representational model (Grune-Yanoff 2013)_, into actual initial conditions, process, and result, that is, a real markets behaviour. Some of the initial conditions needed to activate certain mechanism typically are at work in the markets, while others not, and they required to be provoked in some way in order to trigger the appropriate chain of events that produces the wanted outcome, that is, the one implied by the model. Such a trigger normally is a certain order or trades, which generate a sequence of reactions that changes the state of a financial system at a given time $t$ and lead to the outcome expected by the theoretical product.

\section{A Philosophical Crash? The Financial Collapse of Prediction, Description and Control}

If we accept that reverse finance is a reasonable way of accounting for specific financial dynamics, it follows that there are cases where the notion of prediction, description (representation), and control (manipulation) might collapse into each other.

In effect, the nature of the relations between models and data, reality and theoretical product-the liaisons dangereuses (Ippoliti 2019) — paves the way for possible manipulation of stock markets through an appropriate use of models. In fact, since neither data nor models, at least in certain

\footnotetext{
3 'Natural' here means the initial conditions and processes that better fit a specific financial set-up at a given time $t$.
}

circumstances, are simply representations or descriptions of a system, the reversal becomes possible and the boundaries between performativity and manipulation get very thin in certain circumstances, especially at micro level or timescale.

Of course, not every model can be inverted and push a market to produce the model's expected outcome, but this possibility increases under certain initial conditions. For instance, this possibility can be increased by two factors: the time-lapse between when the model makes its prediction and when the predicted event should happen, and how much a market is run by algorithms (Ippoliti 2019).

In effect, we can obtain a prediction even from a nonrepresentational model, and then make the initial conditions required by this model real and actual, so to temporarily control a market by performing the outcome implied by the model. Thus, the prediction of a possible results can become a description, and the description can become a way of controlling temporarily a market. In this way, we can engineer an intended outcome by looking for the most 'natural' model that would produce that outcome under a specific financial setting. In this case, reverse finance it is a way to understand how to change the actual settings (normative, practical, technological) or to design it so to get an intended outcome. In this case, prediction, representation and control would be reversible processes, and you can could move from one to the other, get one from the other, in a way that is not possible in other scientific or social domains.

\section{Philosophy for Finance}

Every theory has to perform a philosophical task, that is, to build:

- An ontology (a set of beliefs about the world, i.e. assertions about the nature of financial institutions and their relationships);

- An epistemology (a set of assertions about what we may know and how we can get to know it);

- A methodology (a set of assertions on how to determine what counts as justified knowledge, and a set of rules or conditions that must be met for something to be considered scientific).

The debates involving these three dimensions are central also in finance and in the philosophical approaches to it. In the next sections, I will outline some of the main philosophical problems in finance and the contribute given to them by the papers in this volume, in particular in ontology, ethics, mathematical modelling and the use of machines in finance. 


\subsection{Ontology}

The financial world is populated by several entities, where a financial entity is defined as one providing financial brokerage, that is, offering loans, capital investments, insurance. The main financial institutions are banks (brokerage, investment, savings), insurance companies, central banks, funds (pension, investment). These entities are also known as financial institutions and have different functions, roles and scopes, which aim at creating a system of check and balance that ensures the smooth functioning of financial systems. In addition to those, financial ontology is characterized by other entities and relationships that shape current financial systems, namely the financial assets. Examples of financial assets are credit agreements such as bonds, equity such as stocks, or derivatives (futures, options, ABS, swaps, CDO).

Tellingly, the debates about ontological issues have become more intense in financial theories recently. One of the reasons for this is the impact of algorithmic finance, which has changed market dynamics especially in stock markets in a way that has undermined the ontological status of fundamental entities. For instance, the very notion of 'quote' has an unclear ontological status as it can be no more the expression of (real) demand and offer because of the specific way computers submit and manage orders (O'Hara 2010).

Moreover, other financial entities are more and more ever changing and their distinction, relations and functions, have being blurred so that their ontological status is less clear nowadays. For example, some Central Banks (e.g. Japan and Switzerland) have become more and more financial players, i.e. they invest in the markets, so to increasingly resemble an investment bank: they do buy not only gold, but also shares of companies like Google, Apple, Facebook, Microsoft.

These permeable boundaries between entities and their functions cause concern as they can trigger consequences that are difficult to predict. The fact that a private company is partially run by a central bank is full of potential conflicts of interest, and it contrast with the way most of the developed countries have conceived the relationship between markets and public institutions.

As Glen Lehman and Chris Mortensen notes in their contribute to this volume, Finance, Nature and Ontology, the ontological debates about finance are shaped by two basic philosophical approaches- 'instrumentalist' and 'realist'. Their paper examines how these two approaches produce different understanding of what is a good society and what is 'Nature' and how new roles for finance and government are proposed to align human relationships with Nature and environmental precautionary principles. The paper ends up arguing that reliance on the impersonal market forces won't save the planet.

Ontological assumptions mold the content of a theory, but in financial system this relation taka a special form because of performativity. Thus, Ivan Boldyrev's paper, The Ontology of Uncertainty in Finance: The Normative Legacy of General Equilibrium, investigates in detail how the ontological and normative presuppositions shape general equilibrium under uncertainty in Arrow's state-contingent approach to pricing commodities. In showing how theoretical thinking about finance underlies institutional developments in finance, this paper offers a complement to the familiar narrative of the performativity of economics and displays the connection between ontology and performativity.

\subsection{Methodology}

A way of conceptualizing financial systems in terms of methods is by using either an internal or external view (Ippoliti 2017a, b). The external view maintains that we can make sense of financial markets by looking for patterns and regularities in sets of data, and it holds that it can be detected and studied through a mathematical lens. The internal view maintains that in order to study, understand, and profit from financial markets, it is necessary to acquire as much knowledge as possible about their internal machinery: rules of trade executions, laws, institutions, regulators, the behavior and psychology of traders and investors. Mathematics does not necessarily play a central role here.

Following this line of reasoning, Ping Chen in his paper Market Uncertainty, Information Complexity, and Feasible Regulation: An Outside View of Inside Study of Financial Market argues that the view from inside improves our understanding on failures in financial market and their regulation. The most critical issue in finance, continues Chen, is information uncertainty and complexity: evidence from inside reveals the current limitations of financial data mainly in the short-term price changes, and quantitative analysis reveals severe instability in high frequency trading and derivative market. Thus, he concludes that feasible regulation should aim at encouraging new technology and sustainable growth, rather than protect obsolete technology and short-term speculation, and that the most fundamental challenge to sustainable economic order is the excessive size of the derivative markets that crowds out investment in real economy.

Catherine Greene, in her paper Differential Information, Arbitrage, and Subjective Value, deals with a typical methodological problem in finance, that is determining if there is such a thing as an 'intrinsic' value of financial assets. She explores some of the subjective factors involved in the calculation of this value and their implications for the Law of One Price-stating that investors should not pay different prices for the same investment. She notes that if subjectivity is involved in the calculation of intrinsic value, then two investors can rationally disagree about the value of a security. This implies that arbitrage opportunities may not always be instances of irrationality, or genuine mispricing, but reflect 
different investor's perceptions of the security. Since a security plays a number of roles in a portfolio, depending on investors' strategy, different investors will be working with different data in their assessment of intrinsic value. Thus, she concludes that the same security can be traded at different prices because different investors do not see it as the 'same thing' at all.

\subsection{Ethics}

The centrality of financial system in modern society makes issues about their fairness for the parties involved in it crucial. In effect, despite the recent efforts, financial markets are affected by injustice, unfairness, discrimination (see e.g. De Bruin et al 2018; Garonna and Spaolonzi 2016). Boudewijn de Bruin, in his paper Epistemic Injustice in Finance, examines a form of injustice in financial markets, that is, gender and racial disparity. He proposes 'testimonial injustice' as a way of explaning some of the existing forms of racial disparity and shows how prejudices about gender and finance decrease epistemic self-confidence, and how this leads to gender disparity.

One of the main factors of unfairness in financial markets is the wealth concentration that they seem to promote, and Paolo Barucca, in his A fair governance. On inequality, power and democracy, discusses how the competing environment of financial markets produces quickly growing creatures that old nation-states struggle to understand, monitor and, consequently, regulate. He analyses the basic mechanisms for the persistence of wealth concentration and advances ways of counter-acting it.

\subsection{Mathematical Modelling}

The idea of mathematical modelling of financial phenomena is relatively recent and it plays a crucial role to understand and predict their dynamics. In effect, not every theory on financial systems ends up with a mathematical account of it, and not every mathematical theory can provide useful predictions (e.g. fractal theory). Emiliano Ippoliti, in his Mathematics and Finance: some Philosophical Remarks provides an analysis of the role that mathematics plays in understanding and modelling finance, especially stock markets, and how philosophy affects it. He outlines how mathematics penetrates finance via physics, constructing a 'financial physics', and examines the philosophical backgrounds that guided this process, in particular the "philosophy of equilibrium' and that of critical points or 'out-of-equilibrium'. In more detail, he shows a few weaknesses of these attempts of mathematization of the financial systems and compares two ways (top-down and bottom-up) of building mathematical approaches to financial systems. He also discusses two important issues emerging from a mathematical approach to finance, that is, the performative and the reversing side of mathematics, and a consequent ethics of mathematics, that is, a responsible construction and use of mathematical products in finance.

A standard mathematical tool employed to account for financial systems is the Brownian motion, which is the object of Christian Walter's The Brownian Motion in Finance: An Epistemological Puzzle. In his paper, Walter notes that Brownian motion has been the benchmark theory of mathematical finance in risk modelling for more than fifty years, despite a lot of statistical results that contradict it. To explain this surprising fact, he puts forward two hypotheses: a mental model irrigating financial academics and practitioners-i.e. the "principle of continuity" developed by Marshall—and the concept of "financial Logos", a discourse that structures practices and organizations, calculations, prudential regulations and accounting standards.

Whether the current mathematical approaches to finance are appropriate ways to advance knowledge or not is a main issue in financial theories. As Ippoliti notes in his paper, a typical way to build a mathematical account of financial phenomena is the top-down approach to it, that is, the one that employ two strategy:

1. It starts from an existing mathematical theory and then, on the basis of certain similarity between the financial phenomena and those treated by such a mathematical theory (e.g. statistical physics), constructs a financial model by treating the former as the latter.

2. It assembles certain axioms to create a plausible word and then derives consequences form it.

In this line of argument, Giulia Miotti's paper Model Building and Problem Solving: A Case from Libor Market Derivatives, analyses two different knowledge-advancing strategies usually adopted at the frontier of knowledge, i.e. problem-solving and model-building, and applies and evaluates them in finance by discussing a case study from the Libor market.

\subsection{Machines and Finance}

A big issue in finance and the philosophical accounts of it is the role played by machines and algorithms. The increasing use of socio-technical devices and algorithmic trading has changed markets dynamics and structure (also at micro level, see O'Hara 1995), with several and controversial pros and cons (e.g. Rao 2007; Folger 2019). On one hand, a line of argument maintains that algo-trading can improve the quality of markets because it increases volumes and liquidity, and so their functioning becomes more systematic and disciplined. Their main benefits are at least three: to discover 
the right asset price faster, stabilize the market, and make it more efficient and rational.

A recent stance maintains that algo-trading raises worrying scenarios involving manipulation and instability. In effect, on one hand, it is not clear that the spread of automated trading contributes to the stabilization of markets. As a matter of fact, the HFT would show otherwise, as the increase in flash crashes and mini flash-crashes seems to be linked to the ascent of automated trading.

Moreover, the interaction between algorithms creates virtual markets where endogenous phenomena arise, develop and end only because of the action of algorithms and their orders, and not of 'real' economic phenomena. These endogenous dynamics makes financial markets susceptible to manipulation especially at short time scales. A side effects of this is the increasing presence of performative and reversing dynamics in the financial system. No surprise then that a lot of efforts has been devoted to account for and regulate algorithmic trading.

Thus Mark Lenglet, in his paper Algorithmic Finance, Its Regulation, and Deleuzean Jurisprudence: A Few Remarks on a Necessary Paradigm Shift, discusses the practice of financial regulation in contemporary financial markets, while a new normative order has emerged. This order, heralded by algorithmic technologies, changes the conditions for the exercise of regulation. In particular Lenglet examines how computers introduce a new normative order in contemporary markets, and he notes that this produces a paradigm shift, whereby a norm, previously explicated with recourse to interpretation, is now replaced by an order characterized by calculation, and discusses the consequences of it.

Moreover, the technological innovations are creating scenarios where machines seem able to run themselves, at least temporarily. This scenario is discussed by Wessel Reijers and collaborators in their paper, Now the Code Runs Itself: On-Chain and Off-Chain Governance of Blockchain Technologies. The authors discuss how blockchain technologies are impacting the issue of governance by focusing on questions that might arise between a strictly "on-chain" governance system and applications of "off-chain" governance, and they illustrate some of the problems and vulnerabilities that emerge from the application of on-chain governance. These issues, of course, are still being debated, but our knowledge remains narrow despite the recent proliferation of theories. That knowledge is increasingly important since it is now even more difficult to understand and regulate financial markets because models, machines, and ethical and methodological concerns affect the way they are organised.

\section{References}

Ackert L, Deaves R (2009) Behavioral finance: psychology, decisionmaking, and markets. Cengage Learning Inc, Mason
Boldyerv I, Ushakov A (2016) Adjusting the model to adjust the world: constructive mechanisms in postwar general equilibrium theory. J Econ Methodol 23(1):38-56

Brisset N (2018) Models as speech acts: the telling case of financial models. J Econ Methodol 25(3):1-21

Brisset N (2019) Economics and performativity: exploring limits, theories and cases. Routledge, London

Brook Y (2011) The morality of money lending: a short history. In: Ghate D, Ralston RE (eds) Why businessmen need philosophy. Penguin, New York, pp 98-109

De Bruin B, Herzog L, O'Neill M, Sandberg J (2018) Philosophy of money and finance. In: Zalta EN (ed) The stanford encyclopedia of philosophy. Stanford University, Stanford

Callon M (2007) What does it mean to say that economics is performative? In: MacKenzie D, Muniesa F, Siu L (eds) Do economists make markets? On the performativity of economics. Princeton University Press, Princeton, pp 310-357

Callon M (1998) Introduction: the embeddedness of economic markets in economics. In: Callon M (ed) The laws of the markets. Blackwell, Oxford

Epstein GA (2005) Financialization and the world economy. Edward Elgar Pub, Cheltenham

Fama EF (1970) Efficient capital markets: a review of theory and empirical work. Journal of Finance 25(2):383-417

Ferguson N (2008) The ascent of money: a financial history of the world. Penguin, New York

Folger J (2019) Automated trading systems: the pros and cons. Investopedia. https://www.investopedia.com/articles/trading/11/automatedtrading-systems.asp

Friedman TL (1999) The lexus and the olive tree: understanding globalization. Farrar Straus \& Giroux, New Yorl

Garonna P, Spaolonzi F (2016) Ethics in finance, finance in ethics. LUISS University Press, Roma

Grune-Yanoff T (2013) Appraising non-representational models. Philos Sci 80(5):850-861

Ippoliti E (2019) Models and data in finance: les Liaisons Dangereuses. In: Nepomuceno Fernández Á, Magnani L, Salguero-Lamillar FJ, Barés-Gómez C, Fontaine M (eds) Model-based reasoning in science and technology. Springer, Berlin, pp 393-406

Ippoliti E (2017a) Method and finance. a view from outside. In: Chen P, Ippoliti E (eds) Methods and finance: a unifying view on finance, mathematics and philosophy. Springer, Berlin, pp 3-15

Ippoliti E (2017b) Method and finance: a view from inside. In: Chen P, Ippoliti $\mathrm{E}$ (eds) Methods and finance: a unifying view on finance, mathematics and philosophy. Springer, Berlin, pp 121-128

Ippoliti E (2020) Un filosofo a wall street. Egea, Milano

Keynes JM (1936) The general theory of employment, interest and money. Harcourt Brace and Co, New York

Kinley D (2018) Necessary evil: how to fix finance by saving human rights. Oxford University Press, Oxford

Lo AW (2004) The adaptive markets hypothesis. J Portf Manag 30:15-29

MacKenzie D (2006) An engine, not a camera. How financial models shape markets. MIT Press, Cambridge

MacKenzie D, Muniesa F, Siu L (2008) Do economists make markets?: On the performativity of economics. Princeton University Press, Princeton

Mas-Colell A, Whinston MD, Green JR (1995) Chapter equilibrium and its basic welfare properties. Microeconomic theory. Oxford University Press, Oxford

Minsky H (1980) Capitalist financial processes and the instability of capitalism. J Econ Issues 14(2):505-523

O’Hara M (1995) Market microstructure theory. Blackwell, Cambridge

O'Hara M (2010) What is a quote? J Trading 5(2):10-16

Rao SK (2007) Algorithmic trading: pros and cons. Tata Consultancy Services, Washington, D.C.

Smith A (1759) The theory of moral sentiments. Bell, Edinburgh 
Sornette D (2003) Why stock markets crash. Princeton University Press, Princeton

Soros G (1987) The alchemy of finance. Wiley, Hoboken

Svetlova E (2012) On the performative power of financial models. Econ Soc 43(2):418-434

Svetlova E, Dirksen V (2014) Models at work-models in decision making. Sci Context 27(4):561-567
Publisher's Note Springer Nature remains neutral with regard to jurisdictional claims in published maps and institutional affiliations. 